\title{
IMPLEMENTAÇÃO DA GESTÃO ESCOLAR E SUAS INTERFACES REVELADAS NOS DOCUMENTOS OFICIAIS DO MUNICÍPIO DE SANTA BÁRBARA
}

\author{
$\underline{\text { Iane Cunha Oliveira }^{1} \text {; Solange Mary Moreira Santos }}{ }^{2}$
}

1. Bolsista PIBIC/CNPq, Graduanda do curso de Licenciatura em Pedagogia, Universidade Estadual de Feira de Santana, e-mail: yanneq@ hotmail.com

2. Orientadora, Departamento de Educação, Universidade Estadual de Feira de Santana, email: solangemmsantos@gmail.com

PAlAVRAS-ChAVE: Gestão Escolar. Política Pública. Eleição de diretores.

\section{INTRODUÇÃO}

$\mathrm{Na}$ atualidade, a gestão escolar tem se tornado um elemento fundamental no processo de democratização da escola, se constituindo como mediadora das exigências externas e das decisões internas da escola que interferem diretamente na organização e administração da escola, além de possuir relevante relação com as políticas educacionais.

Gestão escolar relaciona-se a uma atuação que tem como foco promover a organização, mobilização e articulação das condições essenciais para garantir o avanço do processo socioeducacional das instituições de ensino e possibilitar a promoção da aprendizagem dos estudantes de forma efetiva.

A gestão escolar tem relevância política e cultural, pois o processo gestionário abarca a totalidade das relações que ocorrem no interior das instituições de ensino e entre estas e a sociedade, ou seja, busca atender às exigências de todos os setores que envolvem essas práticas, desde funcionários, estrutura física da escola até em relação aos pais e alunos e o clima destes com o ambiente educacional, busca também promover o ensino e a aprendizagem para todos.

Para que o Estado cumpra seu papel na garantia dos direitos aos cidadãos, desde a saúde, a segurança, a educação, dentre outros, fazendo com que estes direitos sejam de qualidade e acessíveis a todos, é necessária a existência de políticas públicas eficazes para que esse propósito possa ser efetivado. Ferreira; Santos (2014) afirmam que as Políticas Públicas Educacionais estão ligadas à qualidade da educação e a sua construção cidadã.

\section{MATERIAL E MÉTODOS OU METODOLOGIA}

Para a realização desta pesquisa foi utilizada a abordagem qualitativa do tipo descritiva, procurando conhecer a realidade e as concepções norteadoras da implementação 
da gestão escolar do município de Santa Bárbara. Godoy (1995) destaca algumas características que balizam a pesquisa qualitativa, as quais também embasam este trabalho, que:

Envolve a obtenção de dados descritivos sobre pessoas, lugares e processos interativos pelo contato direto do pesquisador com a situação estudada, procurando compreender os fenômenos segundo a perspectiva dos sujeitos, ou seja, dos participantes da situação em estudo (GODOY, 1995, p. 58).

Sobre isto, esta pesquisa é conceituada como um processo de análise da realidade através da utilização de métodos para a compreensão detalhada do objeto de estudo em seu contexto histórico.

Recorremos à pesquisa documental que, de acordo com Oliveira (2007), caracteriza-se pela busca de informações em documentos que não receberam nenhum tratamento científico. Partindo do pressuposto de que os documentos analisados se constituem em um objeto inerte e neutro, nota-se que, então, esse objeto está imbuído de significados, crenças, percepções e interpretações historicamente situadas. Dessa forma, possibilita a compreensão contextualizada do ponto de vista histórico e sociocultural da gestão escolar do município de Santa Bárbara.

Os documentos normativos são, por si mesmos, moduladores de práticas, mas não devem ser vistos como unilateralmente construídos, porque eles também resultam de um contexto sócio-histórico e envolvem discursos na sua composição. Dessa forma, foram analisados os documentos oficiais que tratam da gestão escolar do município investigado, disponibilizados pela Secretaria de Educação da cidade referida, que foram produzidos pelos poderes legislativos e executivos, no período de 1990 a 2015.

\section{RESULTADOS E/OU DISCUSSÃO}

Nos documentos disponibilizados pela Secretaria Municipal de Educação de Santa Bárbara, a Lei $n^{\circ}$ 279, sancionada em 09 de outubro de 1997, estabelece a criação do Conselho Municipal de Educação, com o objetivo de mediar a relação entre a sociedade e os gestores da Educação Municipal. Essa é uma das primeiras leis criadas no município e se encontra redigida de modo manuscrito.

Em 2003, houve uma atualização da Lei Orgânica nº 001/2003, sendo que essa é a lei mais importante do município, sendo uma espécie de Constituição Municipal. No que se refere à gestão escolar, a Lei Orgânica do município dispõe no Art. 155 que a organização do Sistema de Ensino do Município é baseada em algumas diretrizes, como destaca o inciso III do $\operatorname{Art}^{\circ}$ 155: "gestão democrática, garantindo a participação de entidade da comunidade na 
concepção, execução e avaliação dos processos educacionais" (SANTA BÁRBARA, 2003, p.18). Sendo assim, essa lei contempla a gestão democrática como prática na escola.

Em seguida, no ano de 2011, foi criada a Lei $n^{\circ} 458$ que institui e estrutura os princípios e normas do plano de cargos, carreira e vencimentos dos profissionais do magistério da rede pública municipal de ensino. Um dos princípios contidos nessa lei é a garantia da gestão democrática do ensino público municipal.

A Lei Municipal $n^{\circ} 520$ que aprova o Plano Municipal de Educação (PME) foi sancionada em 2015, com a duração de 10 anos. O Art. $2^{\circ}$ dessa lei traz as diretrizes do PME, sendo que o inciso VI traz a promoção do princípio da gestão democrática da educação pública. Frente às dimensões contidas nesse PME, há a seguinte citação:

\begin{abstract}
"[...] cabe observar que a gestão e o financiamento são instrumentos fundamentais e imperativos para que a política educacional para os próximos dez anos, aqui traçada, seja implementada. Nesse sentido, a política de gestão democrática representa um importante papel, através do Conselho Municipal de Educação e demais colegiados da educação, sociedade civil organizada, instâncias da mais alta relevância, porquanto representam, não só o controle social e fiscalização da aplicação dos recursos financeiros, mas parceiros para a consecução das estratégias e metas que se pretende alcançar." (SANTA BÁRBARA, 2015, p. 09).
\end{abstract}

Esse documento elenca algumas ações que, sendo efetivadas, afiançarão de forma qualitativa a Educação do Município. Uma dessas é o estabelecimento de Diretrizes, Estratégias e Metas para a Gestão Democrática do Ensino Público, sendo que uma dessas metas é o fortalecimento da gestão democrática, que tem dois objetivos: assegurar, durante a vigência desse plano, a gestão democrática nas escolas e na SEDUC; fortalecer, durante a vigência desse plano, os conselhos de educação, conselho escolar e estimular a criação de grêmios estudantis.

Ainda em 2015 foi aprovada a Lei $\mathrm{N}^{\circ} 523$ que dispõe sobre a implementação do Conselho Escolar nas Escolas Públicas do município em questão. Em seu art. $3^{\circ}$ diz que "o Conselho Escolar constitui-se no órgão máximo da gestão escolar e exercerá as funções consultiva, deliberativa, fiscalizadora, propositiva e mobilizadora nos assuntos referentes à gestão pedagógica, administrativa e financeira da unidade escolar [...]” (SANTA BÁRBARA, 2015, p. 02). Sendo assim, uma das atribuições do Conselho Escolar é fiscalizar a gestão administrativa, pedagógica e financeira da escola.

$\mathrm{O}$ discurso recorrente nos documentos analisados apresenta argumentos que defendem a gestão escolar autônoma com o objetivo de melhorias do ensino, fundando-se em preceitos democráticos, "que desmanche a estrutura hierarquizada e autoritária que inibe as relações pedagógicas" (PARO, 2001, 15). Assim, essa gestão democrática visa a participação e que 
todos os segmentos da comunidade sejam inclusos na gestão e que considerem seus interesses e opiniões.

\section{CONSIDERAÇÕES FINAIS}

Com base nesta pesquisa, foi possível realizar a análise dos documentos legais do município de Santa Bárbara, além de compreender como a gestão escolar está normatizada e de conhecer a realidade educacional, que está contida nos documentos dessa cidade. Os resultados retratam que os regimentos da educação de Santa Bárbara defendem a promoção do princípio da gestão democrática da educação pública, bem como a participação de profissionais de educação, de pais e de alunos, na elaboração das decisões que precisam ser tomadas na organização escolar.

Diante do exposto, fica evidente que o município se preocupa com a qualidade do ensino dos sujeitos e seus documentos normativos são bem elaborados, contudo o que está posto em lei precisa ser colocado em prática a ponto de vir a se concretizar, por exemplo, a participação da comunidade escolar nas decisões educacionais.

O município é a base e o ponto de partida para a construção de uma educação com qualidade social, pois essa é um caminho impulsor do desenvolvimento local, regional e nacional. Partindo desse pressuposto, cumpre salientar que os dados dessa investigação sobre a gestão escolar, no que diz respeito a sua regulamentação no município de Santa Bárbara, nos permite concluir que esse processo gestionário busca nos seus documentos a construção da autonomia, participação e democratização.

\section{REFERÊNCIAS}

FERREIRA, Cleia Simone; SANTOS, Everton Neves dos. Políticas Públicas Educacionais: Apontamento sobre o direito social da qualidade na educação. In: Revista LABOR, v. 1, n ${ }^{\circ}$ 11, 2014, p. 146-159.

GODOY, A. S. Introdução à pesquisa qualitativa e suas possibilidades. In: Revista de Administração de Empresas. São Paulo: v.35, n.2, p. 57-63, abril 1995.

OLIVEIRA, Maria M. Como fazer pesquisa qualitativa. Petrópolis, RJ: Vozes, 2007.

PARO, Vitor Henrique. Gestão democrática da escola pública. 3. ed. São Paulo: Editora ática, 2001

SANTA BÁRBARA. Lei $n^{\circ} 182$, de 04 de Abril de 1990. Dispõe sobre Lei Orgânica do Município de Santa Bárbara, Estado da Bahia.

Lei ${ }^{\circ}$ 520/2015. Dispõe sobre a aprovação do Plano Municipal de Educação PME - do Município de Santa Bárbara - BA, em consonância com a Lei № 13.005/2014 que trata do Plano Nacional de Educação - PNE e dá outras providências.

Lei $n^{\circ}$ 523/2015. Dispõe sobre a implementação e organização do Conselho

Escolar nas escolas Públicas Municipais de Santa Bárbara. 